\title{
Responses of advanced directives by Jehovah's Witnesses on a gynecologic oncology service
}

This article was published in the following Dove Press journal:

Journal of Blood Medicine

24 December 2014

Number of times this article has been viewed

\author{
Nimesh P Nagarsheth ${ }^{1,2}$ \\ Nikhil Gupta ${ }^{3}$ \\ Arpeta Gupta ${ }^{4}$ \\ Erin Moshier ${ }^{5}$ \\ Herbert Gretz' \\ Aryeh Shander ${ }^{6}$
}

'Division of Gynecologic Oncology,

Department of Obstetrics,

Gynecology and Reproductive

Science, Icahn School of Medicine

at Mount Sinai, Mount Sinai Medical

Center, New York, NY, USA;

${ }^{2}$ Englewood Hospital and Medical

Center, Englewood, NJ, USA;

${ }^{3}$ Department of Urology, North

Shore - Long Island Jewish Health

Service, New Hyde Park, NY, USA;

${ }^{4}$ Department of Endocrinology,

Diabetes and Metabolism, St

Luke's Hospital of Kansas City,

Kansas City, MO, ${ }^{5}$ Department of

Preventive Medicine, Icahn School of Medicine at Mount Sinai, Mount Sinai Medical Center, New York, NY, USA; ${ }^{6}$ Department of Anesthesiology, Englewood Hospital and Medical

Center, Englewood, NJ, USA
Correspondence: Nimesh P Nagarsheth Division of Gynecologic Oncology, Department of Obstetrics, Gynecology and Reproductive Science, Mount Sinai Medical Center, II 76 Fifth Avenue, Box I I73, New York, NY 10029-6574, USA

Tel +l $21224 \mid 6554$

Fax + I 2129876386

Email nimesh.nagarsheth@gmail.com
Objectives: To review the responses of advance directives signed by Jehovah's Witness patients prior to undergoing surgery at a gynecologic oncology service.

Study design: A retrospective chart review of gynecologic oncology patients undergoing surgery at a bloodless surgery center from 1998-2007 was conducted. Demographic, pathologic, and clinical data were recorded. The proportion of patients who accepted and refused various blood-derived products was determined and was compared to previously published results from a similar study of labor and delivery unit patients.

Results: No gynecologic oncology patients agreed to accept transfusions of whole blood, red cells, white cells, platelets, or plasma under any circumstance, whereas $9.8 \%$ of pregnant patients accepted transfusion $(P=0.0385)$. However, $98 \%$ of gynecologic oncology patients agreed to accept some blood products, including fractions such as albumin, immunoglobulins, and clotting factors, while only $39 \%$ of pregnant patients agreed $(P<0.0001)$. In addition, all gynecologic oncology patients (100\%) accepted intraoperative hemodilution, compared to 55\% of pregnant patients $(P<0.0001)$.

Conclusion: Our results confirm the commonly held belief that the majority of Jehovah's Witness patients refuse to accept major blood components. However, Jehovah's Witness patients at a gynecologic oncology service will accept a variety of blood-derived products (minor fractions) and interventions designed to optimize outcomes when undergoing transfusion-free surgery. Patients presenting to a gynecologic oncology service respond differently to advanced directives related to bloodless surgery, as compared to patients from an obstetrical service.

Keywords: Jehovah's Witness, bloodless surgery, advanced directives

\section{Introduction}

Jehovah's Witness patients present a significant challenge to the gynecologic surgeon. Because of their religious beliefs, Jehovah's Witnesses typically do not accept transfusions of whole blood, red blood cells, white blood cells, platelets, and plasma. This ban on allogenic blood has been official church doctrine since 1945, ${ }^{1}$ but more recently, the church has significantly modified its stance regarding this issue and currently does allow transfusion of minor fractions of blood based on individual preference. ${ }^{2}$

The field of bloodless surgery and medicine (patient blood management) has rapidly evolved over the past few decades. Starting in 1962, Ott and Cooley ${ }^{3}$ performed more than 500 open-heart surgery procedures on Jehovah's Witness patients without the use of blood transfusions. Methods of blood conservation and bloodless surgery continue to improve with the introduction of new clinical, surgical, and 
pharmacologic strategies. Jehovah's Witness patients and others wishing to avoid allogeneic transfusions now have access to many techniques designed to avoid allogeneic transfusion and to minimize procedure-related blood loss including normovolemic hemodilution and intraoperative autologous blood salvage (performed in a closed system without blood storage). ${ }^{4-8}$ According to the Society for the Advancement of Blood Management, there are currently approximately 100 bloodless surgery centers across the United States. $^{9}$

Because the church encourages Jehovah's Witness patients to decide whether or not to accept minor fractions of blood and other modern interventions, patients often rely on their own personal level of spirituality, family, and support network to reach a comfortable decision. ${ }^{2}$ Jehovah's Witness patients presenting to our gynecologic oncology service through our patient blood management center are no exception. They are asked to complete a detailed advanced directive as part of the preoperative counseling and management (Figure 1). Counseling with individuals trained in bloodless surgery has been a valuable resource for our patients.

We sought to review the responses of the advance directives by Jehovah's Witnesses in order to gain a better understanding of our patients' preferences with regards to interventions related to performing bloodless surgery. In addition, we wanted to compare our results to those from a recent study reporting responses given by pregnant Jehovah's Witness patients admitted to a labor and delivery service in order to determine the potential differences among the pregnant population as compared to patients undergoing surgery at a gynecologic oncology service. ${ }^{2}$ Importantly, the patients in the previous study by Gyamfi and Berkowitz ${ }^{2}$ did not have access to a hospital-based professional counseling service trained in bloodless surgery and medicine.

\section{Methods}

Patients undergoing surgical procedures at the gynecologic oncology service at a patient blood management center were identified over a 9-year period from April 1998-April 2007. This project was approved by the hospital Institutional Review Board.

For the cases identified, charts were reviewed for information regarding the patients' general characteristics, as well as pertinent aspects of the surgeries performed. Data pertaining to preoperative, intraoperative, and postoperative interventions and techniques related to bloodless surgery were collected. Specifically, responses from the advance directives of Jehovah's Witnesses were recorded.

All information collected was placed into a computerized database. A two-samples $t$-test was used to compare the proportion of patients from our study who agreed to accept blood-derived products to that of patients presenting to a labor and delivery unit, as reported previously. ${ }^{2}$

\section{Results}

Forty-one patients were identified and accounted for 43 procedures performed at the gynecologic oncology service. The mean patient age was 58 (standard deviation [SD] \pm 13 ) years and all patients identified themselves as Jehovah's Witnesses. Responses from advance directives of patients are reported in Table 1.

In general, patients received preoperative hemoglobin optimization with iron and folic acid. Erythropoietin was used on an individualized basis when deemed indicated by the attending physician and consented by the patient. The mean preoperative hemoglobin level was $13.5(\mathrm{SD} \pm 1.9) \mathrm{g} / \mathrm{dL}$. The most common procedures were laparotomy (number $[\mathrm{n}]=31 ; 76 \%$ ), salpingo-oophorectomy $(\mathrm{n}=30 ; 73 \%)$, hysterectomy $(\mathrm{n}=30 ; 73 \%)$, and lymph node dissection $(n=17 ; 42 \%)$. Laparoscopy $(n=7)$ was performed in $17 \%$ of patients. Twenty-nine cases $(71 \%)$ were performed for malignancy including advanced ovarian, fallopian tube, or uterine cancers. Mean surgical and anesthesia times were 155.1 ( $\mathrm{SD} \pm 75.4$ ) minutes and 217.7 (SD \pm 81.2 ) minutes, respectively.

Cell salvage was collected in 19 (46\%) of cases, with four patients receiving reinfusion of cell salvaged blood. Of these four patients, three patients had malignancy and reinfusion of blood was performed using a leukocyte depletion filter in an effort to remove cancer cells (detailed outcomes of these three patients with known malignancy receiving cell salvage blood have been reported previously ${ }^{6}$ ). Intraoperative acute normovolemic hemodilution was performed in 19 (49\%) cases. Median blood loss was $200 \mathrm{~mL}$ $(0-2,500 \mathrm{~mL})$ and mean postoperative hemoglobin was 11.3 (SD \pm 2.4 ) g/dL. Major intraoperative and postoperative complications occurred in three patients $(7.3 \%)$ and included hemorrhage $(n=1)$, symptomatic anemia $(n=2)$, necrotizing fasciitis $(n=1)$, bowel perforation $(n=1)$, and thromboembolic events $(n=1)$. The median hospital stay was 4 days (range: 0-95 days).

Our data from the advanced directives show that none of the Jehovah's Witness patients included in this study would 


\section{THE NEW JERSEY INSTITUTE FOR THE ADVANCEMENT OF \\ BLOODLESS MEDICINE AND SURGERY \\ AT ENGLEWOOD HOSPITAL AND MEDICAL CENTER}

\section{ADVANCE DIRECTIVE/INSTRUCTION SHEET}

I direct that NO BLOOD TRANSFUSIONS (whole blood, red cells, white cells, platelets, and/or fresh frozen plasma) are to be given me under $\underline{A N Y}$

circumstances, even if physicians deem such necessary to preserve my life or health. I will accept NONBLOOD volume expanders (such as saline, dextran, Ringer's Lactate solution, or hetastarch) and other nonblood management. The following are my wishes and directions regarding procedures, treatments, and blood fractions (check which):

\begin{tabular}{|l|l|l|}
\hline PRODUCT/TREATMENT/PROCEDURE & ACCEPT & REFUSE \\
\hline Albumin (blood fraction) & & \\
\hline Erythropoietin (contains albumin) & & \\
\hline Immune Globulins (blood fraction) & & \\
\hline Clotting factors (plasma derived fractions) & & \\
\hline Fractional agents derived from platelets, plasma, or hemoglobin & & \\
\hline Topical Tissue Adhesives, Hemostatics, (blood fractions) & & \\
\hline Cryoprecipitates (blood fractions) & & \\
\hline Intraoperative Hemodilution and Fractionation* & & \\
\hline Hemodialysis Equipment/C.V.V.H.* & & \\
\hline Intraoperative autologous blood salvage ("cell-saver")* & & \\
\hline Post-Operative Blood Salvage/Reinfusion* & & \\
\hline Cardiopulmonary bypass (heart-lung machine)* & & \\
\hline Organ Donation & & \\
\hline Organ Transplantation & & \\
\hline
\end{tabular}

Dated this day of (month) , (year)

\section{Signature of Patient}

I declare that the person who signed this document did so in my presence and that he/she appears to be of sound mind and free of duress or undue influence. I am 18 years of age or older, and am not designated by this or any other document as the person's health care representative.

1. Witness

Address

City

Print Name

Date

*Where extracorporeal circulation is a closed system without blood storage

2. Witness
Address__
City
Print Name
Date

\section{OVER $\rightarrow$}

Figure I Bloodless protocol patient instruction sheet.

Notes: The checklist is provided solely as a guide and should not be considered a legal document. This has been adapted from the Bloodless Medicine and Surgery Program Checklist at our institution.

Abbreviation: $\mathrm{CVVH}$, continuous veno-venous hemofiltration.

accept transfusions of whole blood, red cells, white cells, platelets, or plasma under any circumstances. Data regarding responses to minor fractions of blood and other interventions are summarized in Table 1.

We compared our subjects' responses to previously published responses given by Jehovah's Witness patients presenting to an obstetrical service. ${ }^{2}$ It is important to note that the obstetrical dataset we used for comparison was not data collected in this present study. In addition, the advanced directive used in the obstetrical service by
Gyamfi and Berkowitz ${ }^{2}$ was not as detailed as the advanced directive offered to the gynecologic oncology patients in our study. The obstetrics advanced directive had five areas of consideration for patients to respond to: whole blood; some amount of blood products, or no blood; hemodilution; and cell salvage. ${ }^{2}$ The gynecologic oncologic service offered patients 14 areas of consideration despite not directly offering any major blood fractions (Figure 1). Of the Jehovah's Witness patients that presented to the obstetrics service, $9.8 \%$ of respondents accepted whole 
Table I Responses from advance directives of Jehovah's Witnesses

\begin{tabular}{|c|c|}
\hline & $\begin{array}{l}\text { Number (\%) } \\
41 \text { patients }\end{array}$ \\
\hline \multicolumn{2}{|l|}{ Albumin } \\
\hline Accept & $40(98 \%)$ \\
\hline Refuse & I (2\%) \\
\hline \multicolumn{2}{|l|}{ Erythropoietin } \\
\hline Accept & $40(98 \%)$ \\
\hline Refuse & I (2\%) \\
\hline \multicolumn{2}{|l|}{ Immunoglobulins } \\
\hline Accept & 40 (98\%) \\
\hline Refuse & I (2\%) \\
\hline \multicolumn{2}{|l|}{ Clotting factors } \\
\hline Accept & $36(90 \%)$ \\
\hline Refuse & $4(10 \%)$ \\
\hline Not answered & 1 \\
\hline \multicolumn{2}{|l|}{ Fractional agents } \\
\hline Accept & $31(89 \%)$ \\
\hline Refuse & $4(11 \%)$ \\
\hline Not answered & 6 \\
\hline \multicolumn{2}{|c|}{ Topical tissue adhesives/hemostatics } \\
\hline Accept & $39(98 \%)$ \\
\hline Refuse & $\mathrm{I}(2 \%)$ \\
\hline Not answered & 1 \\
\hline \multicolumn{2}{|l|}{ Cryoprecipitates } \\
\hline Accept & $35(88 \%)$ \\
\hline Refuse & $5(12 \%)$ \\
\hline Not answered & 1 \\
\hline \multicolumn{2}{|c|}{ Intraoperative hemodilution and fractionation } \\
\hline Accept & $41(100 \%)$ \\
\hline Refuse & $0(0 \%)$ \\
\hline \multicolumn{2}{|c|}{ Hemodialysis equipment } \\
\hline Accept & $4 I(100 \%)$ \\
\hline Refuse & $0(0 \%)$ \\
\hline \multicolumn{2}{|c|}{ Intraoperative autologous blood salvage } \\
\hline Accept & 40 (98\%) \\
\hline Refuse & I (2\%) \\
\hline \multicolumn{2}{|c|}{ Postoperative blood salvage/reinfusion } \\
\hline Accept & 37 (100\%) \\
\hline Refuse & $0(0 \%)$ \\
\hline Not answered & 4 \\
\hline \multicolumn{2}{|c|}{ Cardiopulmonary bypass } \\
\hline Accept & $36(100 \%)$ \\
\hline Refuse & $0(0 \%)$ \\
\hline Not answered & 5 \\
\hline \multicolumn{2}{|l|}{ Organ donation } \\
\hline Accept & $8(50 \%)$ \\
\hline Refuse & $8(50 \%)$ \\
\hline Not answered & 25 \\
\hline \multicolumn{2}{|c|}{ Organ transplantation } \\
\hline Accept & $8(50 \%)$ \\
\hline Refuse & $8(50 \%)$ \\
\hline Not answered & 25 \\
\hline
\end{tabular}

blood, 39.3\% accepted some blood products, and 50.1\% did not accept any blood or blood products. ${ }^{2}$ For autologous blood, $55 \%$ of obstetrics subjects accepted intraoperative hemodilution and $46 \%$ of obstetrics subjects accepted cell salvage. $^{2}$

\section{Discussion}

The evolution of bloodless surgery and medicine now offers Jehovah's Witness patients an organized approach to surgery designed to minimize blood loss and to avoid blood transfusions. ${ }^{4,8}$ Bloodless surgery is separated into three categories: preoperative; intraoperative; and postoperative interventions. ${ }^{8}$ The preoperative process begins with a thorough history and a detailed physical examination. ${ }^{10}$ Preoperative counseling with informed consent is of paramount importance in managing patients who desire to avoid allogeneic transfusions when undergoing surgical procedures. ${ }^{4}$ In this regard, patients are asked to clearly document which, if any, minor or major fractions of blood they would accept, as well as which bloodless-related preoperative, intraoperative, and postoperative measures they will accept. ${ }^{4}$ Therefore, all bloodless patients are asked to fill out an advanced directive form (Figure 1) as part of the preoperative management at our institution. A detailed discussion of the preoperative, intraoperative, and postoperative measures outlined in the advanced directive form as they relate to our study is provided.

During the preoperative management, hemoglobin levels should be optimized, and efforts should be made to correctly diagnose and treat any existing anemia. Erythropoietin therapy, iron therapy, vitamin supplementation, and administration of other medications are often useful in the preoperative setting and should be considered on an individual basis. ${ }^{8}{ }^{810}$ Because erythropoietin contains a small amount of albumin, which may not be acceptable to certain Jehovah's Witness patients, this medication is specifically addressed on the advanced directive form (Figure 1). Included in the preoperative management, the physician should also minimize blood draws and avoid medications that may interfere with platelet activity such as aspirin and other nonsteroidal antiinflammatory drugs. ${ }^{10}$ The use of pediatric tubes for blood draws may be appropriate, especially if a large number of laboratory tests are being performed..$^{11}$ In select cases, the gynecologic surgeon may consider preoperative uterine artery embolization or balloon catheter placement by interventional radiology in order to minimize surgical blood loss. ${ }^{4}$

Intraoperative management of the bloodless patient is complex and requires a high level of technical skill and excellent communication between the surgical and anesthesia teams. Surgical approaches that reduce blood loss, such as handling tissue gently, recognizing and avoiding potential sources of bleeding, and rapidly controlling unexpected hemorrhage, are essential. ${ }^{10}$ Patient positioning is critical in order to maximize access to the surgical field from multiple approaches. We routinely perform our laparoscopic 
and open abdominal gynecologic surgeries in the dorsal lithotomy position using Allen stirrups to allow access for both abdominal and vaginal surgical approaches. This position also reduces arterial pressure around the surgical site and facilitates venous drainage away from the site..$^{10}$ Other important intraoperative techniques include acute normovolemic hemodilution and intraoperative autologous transfusion (which may be acceptable to some Jehovah's Witness patients when performed in a closed system without blood storage). ${ }^{10,12}$ Because these interventions are not accepted by all patients, they are specifically addressed in the advanced directive form (Figure 1). Importantly, we previously demonstrated the safety and efficacy of cell salvage using leukocyte depletion filters in patients with malignancy as a method to prevent hematogenous dissemination of tumor cells. ${ }^{6}$ In addition, we have recently demonstrated that laparoscopic blood collection is not inferior to the standard Yankauer method for cell salvage collection used in open surgery. Therefore, cell salvage blood collection should be considered in patients undergoing laparoscopic procedures when significant blood loss is anticipated. ${ }^{7}$

Postoperative measures in bloodless surgery include tolerance of anemia and minimization of blood draws. Patients should be monitored closely to check for bleeding and adequate oxygenation..$^{410}$ If the patient requires intensive care, excellent communication with the intensive care unit staff is crucial to the success of the patient. ${ }^{8}$ The use of pediatric blood tubes should be considered when appropriate, and the judicious use of intravenous iron and erythropoietin should also be considered in the postoperative period. ${ }^{8,11,13,14}$ If acute postoperative bleeding is suspected, the surgeon should consider reoperation promptly to identify and treat the source of bleeding. ${ }^{8}$ Although we do not routinely follow hemoglobin levels in the postoperative period in a stable patient, studies have shown a low risk of postoperative mortality in upper nadir hemoglobin ranges of $7-8 \mathrm{~g} / \mathrm{dL}$ and much higher risk in lower ranges. ${ }^{15}$

We demonstrate that differences in advanced directive responses exist between obstetrics patients and gynecologic oncology patients. Fewer obstetrics patients accepted minor fractions of blood than did gynecologic oncology patients; however, more obstetric patients accepted whole blood than did the gynecologic patients. Also, a smaller percentage of obstetric patients accepted hemodilution and/or cell salvage than did the gynecologic oncology patients.

One possible explanation for the discrepancy in advanced directive preferences between the two study populations is inherent to the characteristics of the study populations themselves (obstetrics versus gynecologic oncology). ${ }^{2}$ For example, the obstetrics patients were younger than the gynecologic oncology patients and $45 \%$ of the obstetrics patients were prima gravida. ${ }^{2}$ Intuitively, maternal instinct and a sense of responsibility of wanting to take care of a newborn may account for why this population would be more likely to accept whole blood.

There are many factors that influence individual patient responses on the advanced directive form. The individual freedom that the Jehovah's Witness church provides Jehovah's Witness patients in accepting or rejecting minor blood fractions or modern interventions allows for patients to incorporate their own values and the advice of their own support network in the decision-making process. ${ }^{2}$ In addition, the technical language of an advanced directive may be difficult for certain individuals to comprehend, which could lead to inaccurate documentation of a patient's wishes. Thus, when completing advanced directives, patients should be counseled by physicians and/or trained professionals that are thoroughly familiar with the field of patient blood management. The counselor must understand both the options presented in the advanced directive and the patient's beliefs, as not all Jehovah's Witness patients reject blood or all blood products. ${ }^{2}$ An attending or resident physician not thoroughly familiar or up to date with bloodless medicine and surgery techniques may not be able to take such vagaries into account when counseling patients.

With this in mind, another explanation for the differences in data between the obstetrics service and the gynecologic oncology service could be the nature of the counseling services each hospital or hospital service offered to their patients. The patients that presented to the gynecologic oncology service were admitted to an established bloodless surgery center, with dedicated staff members that were trained specifically for counseling and aiding in the care of Jehovah's Witness patients. The patients that presented to the obstetrical service did not have access to a specialized counseling staff member. Thus, the obstetrical patients were largely dependent on the direction of the resident and attending physicians on the obstetrical service, presumably with little or no specialized training in the field of patient blood management. Without the help of dedicated support staff specializing in bloodless medicine and surgery, the obstetrical patients may have had less guidance and found it more difficult to make such important decisions about their care.

One more possible explanation for the differences in the responses among patient populations is that the advanced directive used by the gynecologic oncology service was much more specific and detailed than the advanced directive used by the obstetrical service in the study by Gyamfi and Berkowitz. ${ }^{2}$ The greater number of queries on the advanced directive made 
available to the oncology study population may have allowed the patients to feel more comfortable, whereas the obstetrical patients may have felt they had fewer choices available to them if a complication were to arise.

The limitations of our study include having a small sample size for our study population, using previously published data from a historical cohort as a comparison, and the inherent biases associated with retrospective chart reviews. In addition, our study encompasses a long time period (1998-2007), during which significant policy changes had occurred at the Watchtower Society. Specifically, in June 2000, the Jehovah's Witness church organization issued a communication stating that the society would no longer disfellowship members who accepted blood, but instead concluded that a member's acceptance of blood would be regarded as a member's voluntary wish to no longer be one of the Jehovah's Witnesses. ${ }^{16}$ The new policy also addressed minor fractions of blood stating that, "when it comes to fractions of any of the primary components, each Christian, after careful and prayerful meditation, must conscientiously decide for himself". ${ }^{16}$ These policy changes may have resulted in patients feeling more comfortable with the idea of accepting minor fractions of blood and could have influenced our results especially with regards to patients undergoing surgery in our blood management program from 2000 onward. These policy changes also highlight the importance of patient confidentiality in this patient population, where personal decision making and community judgment had often previously overlapped. Finally, the fact that patients in our study were likely referred to (or specifically sought out treatment at) a bloodless surgery center may signify that we had a more religious population, and therefore may bias our results toward the direction of blood refusal.

\section{Conclusion}

In conclusion, completion of an advanced directive is an essential component of preoperative patient blood management. By comparing responses on advanced directives from different patient populations, we have shown that significant variations in responses exist among Jehovah's Witness patients. Although several factors may account for the differences noted in this study, we believe that counseling by a dedicated support staff member trained in the field of bloodless surgery plays a critical role. Therefore, counseling performed by individuals with a strong background in blood management interventions and techniques should be readily available to all patients wishing to avoid allogeneic transfusions.

\section{Acknowledgment}

Presented at the 39th Annual Meeting of the Society of Gynecologic Oncologists, Tampa, FL, March 7-12, 2008, and at the Society for Advancement of Blood Management Annual Meeting, Baltimore, MD, September 12-14, 2008.

\section{Disclosure}

The authors report no conflicts of interest in this work.

\section{References}

1. Gyamfi C, Gyamfi MM, Berkowitz RL. Ethical and medicolegal considerations in the obstetric care of a Jehovah's Witness. Obstet Gynecol. 2003;102(1):173-180.

2. Gyamfi C, Berkowitz RL. Responses by pregnant Jehovah's Witnesses on health care proxies. Obstet Gynecol. 2004;104(3):541-544.

3. Ott DA, Cooley DA. Cardiovascular surgery in Jehovah's Witnesses. Report of 542 operations without blood transfusion. JAMA. 1977; 238(120): 1256-1258.

4. Nagarsheth NP, Shander A, Malovany R, Tzeng J, Ibrahim I. Bloodless surgery in a Jehovah's Witness patient with a $12.7-\mathrm{kg}$ uterine leiomyosarcoma. J Surg Educ. 2007;64(4):212-219.

5. Elias D, Lapierre V, Billard V. [Perioperative autotransfusion with salvage blood in cancer surgery]. Ann Fr Anesth Reanim. 2000;19(10): 739-744. French.

6. Nagarsheth NP, Sharma T, Shander A, Awan A. Blood salvage use in gynecologic oncology. Transfusion. 2009;49(10):2048-2053.

7. Nagarsheth NP, Fenske SS, Shah A, Moshier E, Stahl R, Shander A. In vitro analysis of cell salvage blood collection with a laparoscopic suction device. J Minim Invasive Gynecol. 2013;20(1):104-106.

8. Nagarsheth NP, Sasan F. Bloodless surgery in gynecologic oncology. Mt Sinai J Med. 2009;76(6):589-597.

9. Society for the Advancement of Blood Management [webpage on the Internet]. Patient blood management programs. Richmond, VA: Society for the Advancement of Blood Management; 2014. Available from: http://www.sabm.org/programsbystate. Accessed August 12, 2014.

10. Goodnough LT, Shander A, Spence R. Bloodless medicine: clinical care without allogeneic blood transfusion. Transfusion. 2003;43(5): 668-676.

11. Smoller BR, Kruskall MS, Horowitz GL. Reducing adult phlebotomy blood loss with the use of pediatric-sized blood collection tubes. Am J Clin Pathol. 1989;91(6):701-703.

12. Jarnagin WR, Gonen M, Maithel SK, et al. A prospective randomized trial of acute normovolemic hemodilution compared to standard intraoperative management in patients undergoing major hepatic resection. Ann Surg. 2008;248(3):360-369.

13. Juneja V, Keegan P, Gootenberg JE, et al. Continuing reassessment of the risks of erythropoiesis-stimulating agents in patients with cancer. Clin Cancer Res. 2008;14(11):3242-3247.

14. Shander A, Ozawa S, Gross I, Henry D. Erythropoiesis-stimulating agents: friends or foes? Transfusion. 2013;53(9):1867-1872.

15. Shander A, Javidroozi M, Naqvi S, et al. An update on mortality and morbidity in patients with very low postoperative hemoglobin levels who decline blood transfusion. Transfusion. Epub February 17, 2014.

16. Muramoto O. Bioethical aspects of the recent changes in the policy of refusal of blood by Jehovah's witnesses. BMJ. 2001;322(7277): $37-39$. 
Journal of Blood Medicine

\section{Publish your work in this journal}

The Journal of Blood Medicine is an international, peer-reviewed, open access, online journal publishing laboratory, experimental and clinical aspects of all topics pertaining to blood based medicine including but not limited to: Transfusion Medicine; Blood collection, Donor issues, Transmittable diseases, and Blood banking logistics; Immunohematology; Artificial and alternative

blood based therapeutics; Hematology; Biotechnology/nanotechnology of blood related medicine; Legal aspects of blood medicine; Historical perspectives. The manuscript management system is completely online and includes a very quick and fair peer-review system. Visit http://www.dovepress.com/ testimonials.php to read real quotes from published authors.

Submit your manuscript here: http://www.dovepress.com/Journal-of-blood-medicine-journal 